\title{
latrogenic Intramural Dissection of the Esophagus after Insertion of a Laryngeal Mask Airway
}

\author{
Hee Young Kim', Seung-Hoon Baek', Yong Hoon Cho², Joo-Yun Kim', Yun Mi Choi', Eun Ji Choi', \\ Jung Pil Yoon ${ }^{1}$, Jung Hyun Park' \\ Departments of ${ }^{1}$ Anesthesia and Pain Medicine and ${ }^{2}$ Surgery, Pusan National University Yangsan Hospital, Yangsan, Korea
}

In pediatric patients, a laryngeal mask airway (LMA) is usually used during minor surgeries that require general anesthesia. No esophageal injury has been reported after insertion of an LMA. We report a case of an esophageal injury with intramural dissection after an i-ge ${ }^{\circledR}$ (size, 1.5; Intersurgical Ltd.) insertion in a pediatric patient. A 2-month-old male infant was hospitalized for left inguinal herniorrhaphy. After induction of anesthesia, a trained resident tried to insert an i-gel ${ }^{\circledR}$. However, it was only successful after three attempts. Dysphagia was sustained until postoperative day 10 , and the pediatrician observed duplication of the esophagus on gastroendoscopy. However, a whitish mucosal lesion, which looked like a scar, was observed, and previous lesions suggestive of esophageal duplication were almost healed on postdischarge day 11. His condition was diagnosed as dysphagia and esophagitis due to an esophageal laceration, not esophageal duplication. He was scheduled for symptomatic treatment with a proton pump inhibitor. In conclusion, although an esophageal injury or perforation in pediatric patients is rare, an LMA insertion or a procedure such as aspiration or nasogastric tube insertion should be performed gently to avoid a possible injury to the esophagus in pediatric patients.

Key Words: esophageal injury; iatrogenic disease; laryngeal masks

Esophageal injury rarely occurs in children, but it can be fatal, as the mortality rate ranges up to $28 \%$ [1] when progressing to perforation. Esophageal injury occurs usually as result of iatrogenic manipulations [2]. There are some causes leading to esophageal injury, such as an endoscopic dilatation, a gastric tube insertion, an endotracheal intubation, and a respiratory suction catheter $[1,3]$.

In pediatric patients, a laryngeal mask airway (LMA) is usually used during minor surgical procedure. It may develop a sore throat due to pharyngeal wall edema as common complication [4]. However, esophageal injury has not been reported. We report the case of an esophageal injury with intramural dissection after an LMA insertion in pediatric patient.

\section{CASE REPORT}

A previously healthy, 2-month-old male infant whose body weight was $6.3 \mathrm{~kg}$ was hospitalized for inguinal herniorrhaphy. After induction of anesthesia, a trained resident tried to in-

\section{Case Report}

Received: September 22, 2016

Revised: October 13, 2016

Accepted: October 18, 2016

\section{Corresponding author}

Seung-Hoon Baek

Department of Anesthesia and Pain

Medicine, Pusan National University

Yangsan Hospital, 20 Geumo-ro,

Mulgeum-eup, Yangsan 50612,

Korea

Tel: +82-55-360-2129

Fax: +82-55-360-2149

E-mail:md.baeksh@gmail.com

Copyright @ 2018 The Korean Society of Critical Care Medicine

This is an Open Access article distributed under the terms of Creative Attributions Non-Commercial License (http:// creativecommons.org/li-censes/by-nc/4.00 which permits unrestricted noncommercial use, distribution, and reproduction in any medium, provided the original work is properly cited. 

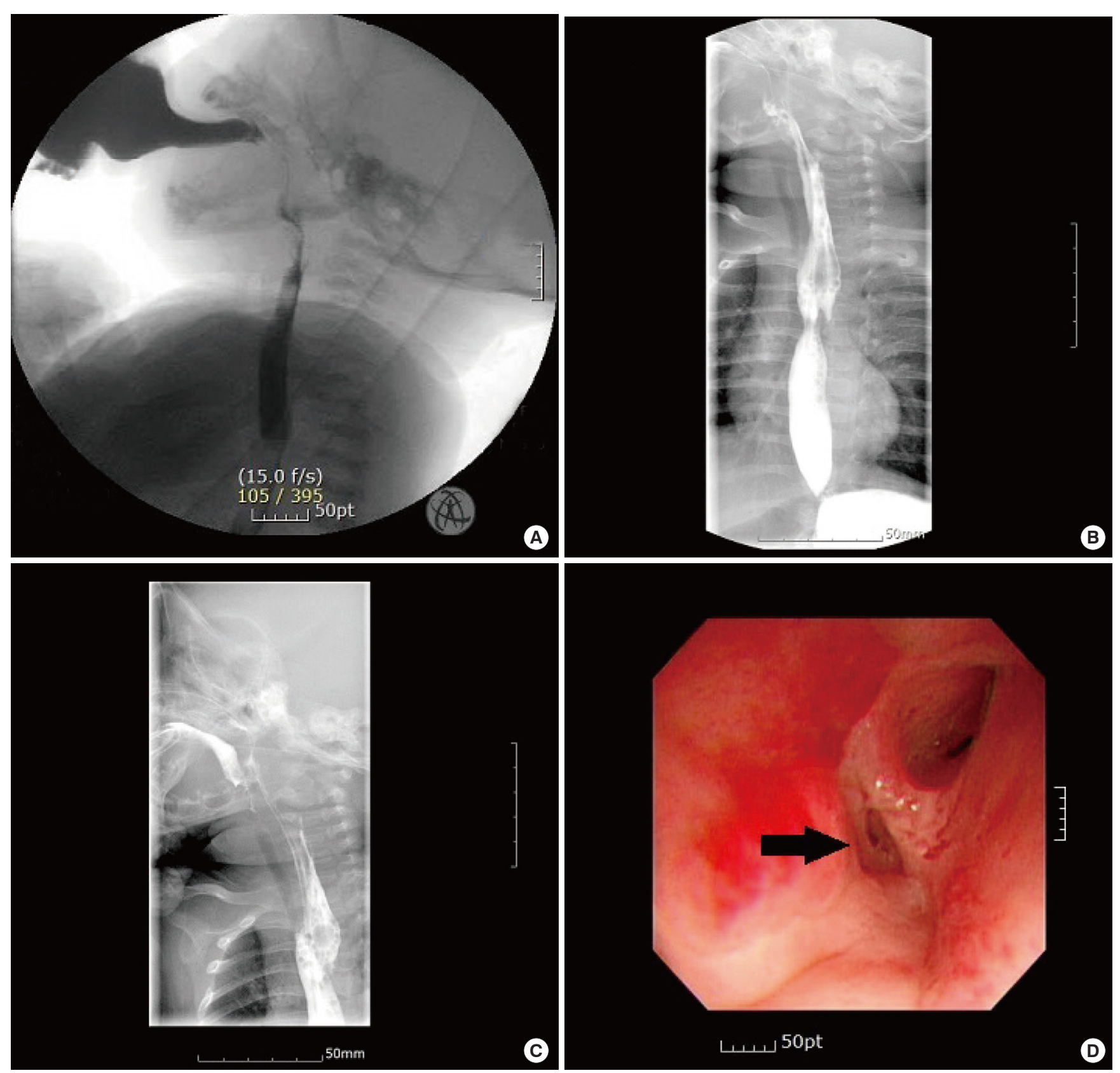

Figure 1. (A) Videofluoroscopic swallowing study results showing aspiration. (B, C) Esophagography findings. Radiocontrast leaked into the left side of the upper esophagus, which was $5 \mathrm{~cm}$ long. (D) Gastroendoscopy findings. An opening (black arrow) was observed from the site that passed from the lower pyriform sinus of the aryepiglottic fold to the upper esophagus.

sert an i-gel ${ }^{\circledR}$ (size, 1.5; Intersurgical Ltd., Wokingham, UK), but the patient could not ventilate via the i-gel ${ }^{\circledR}$, which was considered as failure of the i-gel ${ }^{\circledR}$ insertion. The resident failed to insert the i-gel ${ }^{\circledR}$ during three times trials and another professional anesthesiologist succeeded to insert the i-gel ${ }^{\circledR}$ at next one trial. Secretions of the mouth and pharynx were suctioned via 6 Fr suction catheter (Vygon, Paris, France) which is soft and has open, straight and rounded tip when the i-gel ${ }^{\circledR}$ was removed, and there was no evidence of pharyngeal injury such as bleeding. The patient got a good recovery from anesthesia without event, but had fever and a large amount of secretions at next day.

A videofluoroscopic swallowing study was performed due to constant dysphagia and a symptom of aspiration with pneumonia. It showed an aspiration to trachea and suggestive findings of esophageal diverticulum (Figure 1A). Additionally, eso- 

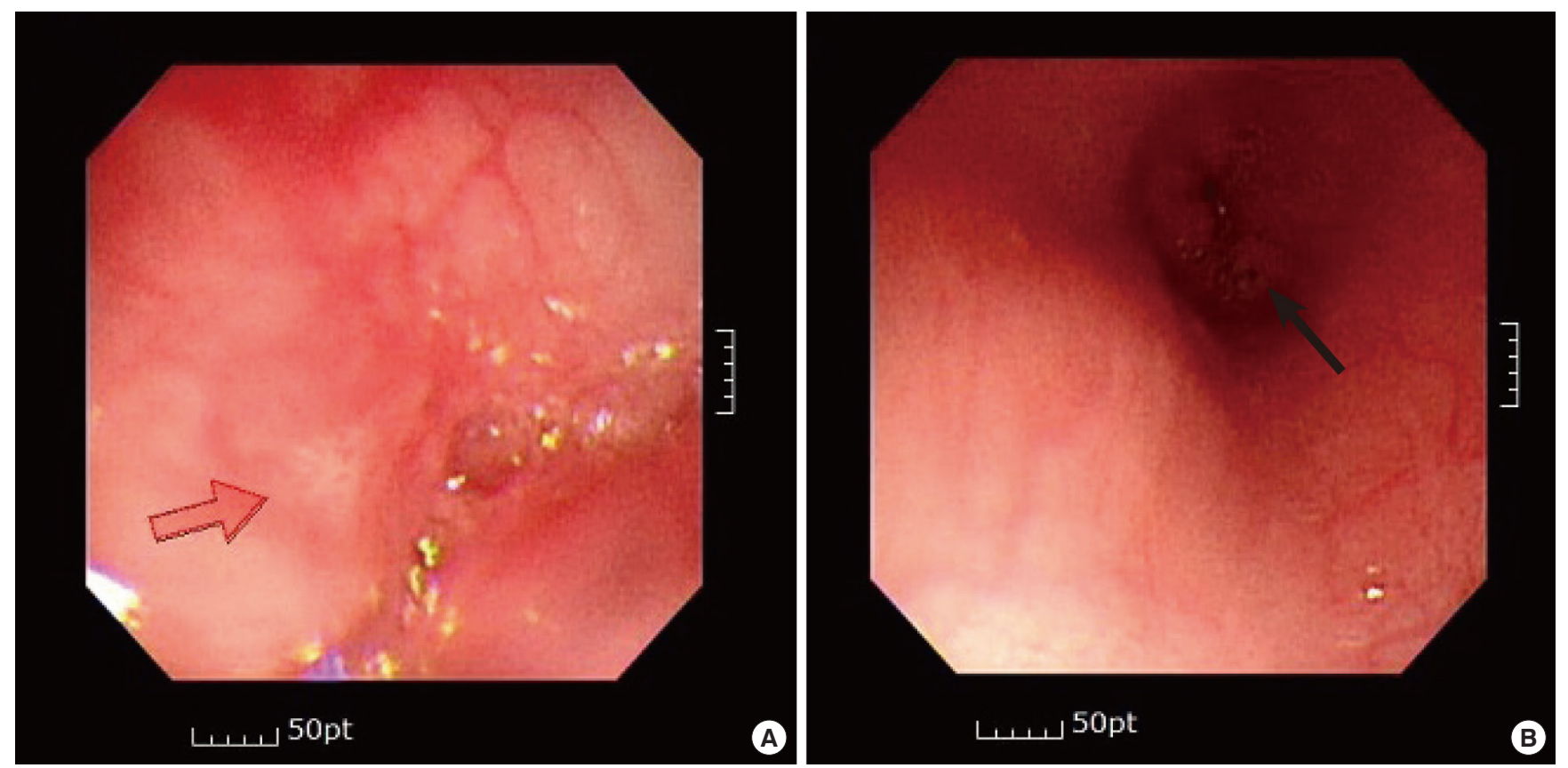

Figure 2. Gastroendoscopy findings on postdischarge day 11. (A) A whitish mucosal lesion (red arrow), which looked like a scar, was observed just below the aryepiglottic fold. (B) Previous lesions suggestive of esophageal duplication were almost healed and were the size of a pinhole (black arrow).

phagography was performed and suggested an esophageal duplication located at the left side of upper esophagus with a $5 \mathrm{~cm}$ length and no distal communication (Figure $1 \mathrm{~B}$ and C). Meanwhile, there was no free perforation or contrast leak during this study. Gastroendoscopy confirmed a communicating hole at upper esophagus and inflammation of surrounded mucosa (Figure 1D).

After confirming, the pediatrician prescribed a proton pump inhibitor, and the patient was discharged in postoperative day 24. During follow-up, gastroendoscopy on postdischarge day 11 showed that a whitish mucosal lesion looked like a scar (Figure 2A) and the previous lesions suggestive of esophageal duplication were almost healed and were the size of a pinhole (Figure 2B). His condition was diagnosed as dysphagia and esophagitis due to an esophageal laceration, not esophageal duplication. He was only scheduled for symptomatic treatment with a proton pump inhibitor.

\section{DISCUSSION}

Esophageal injury associated with a tracheal intubation could occur very rarely [5], but seldom after the insertion of an LMA. In pediatric patients, there are two anatomically weak regions being vulnerable to injury or perforation during procedure; the pharyngoesophageal junction and the Killian's triangle in the cervical esophagus [6]. We could suspect that the injury began near the pharyngoesophageal junction and accompanied with a longitudinal intramural dissection to upper thoracic level. At first, the esophagographic examination suggested a finding to mimic a tubular duplication of upper esophagus.

An esophageal duplication cyst (EDC) may occur in the cervical or abdominal segment, but it commonly occurs in the thoracic segment. A diagnosis is usually made by using endoscopy and an esophagogram, and the presence of an EDC is confi rmed by a histologic examination. Two-thirds of cases with an EDC have ectopic gastric mucosa, which causes ulceration or perforation of the mucosa. In our case, there were two well formed lumens in the upper esophagus, and one of them was closed. The endoscope passed through the other lumen; therefore, an EDC was considered, although an EDC in the cervical segment is rare. However, the finding disappeared spontaneously after conservative management, so the possibility of duplication could be excluded.

Although esophageal perforation in pediatric patients rarely occurs, prompt treatment is necessary, because it can progress to fatal events such as mediastinitis, sepsis, and multiorgan failure. To successfully treat esophageal perforation, it is mandatory to diagnose early. Panieri et al. [3] has reported on the treatment of patients who had damage to the esophagus. 
If the leak is limited to the mediastinum, conservative treatment such as appropriate fluid therapy, respiratory support, fasting, gastric and pleural drainage, and antibioticis is recommended. However, if there is an intrapleural leakage, surgical treatment such as primary closure should be considered. Currently, there has been a trend toward conservative treatment for esophageal perforation in children [7].

In our case, we could guess two possible causes of esophageal injury. One is the insertion of an i-gel ${ }^{\circledR}$ multiple times forcefully, and the other is the suction of secretion in the oral cavity. The use of an LMA during ambulatory surgery, requiring general anesthesia and airway management, has increased, because it is less invasive compared to tracheal intubation and it provides more reliable ventilation than a face mask. However, when it is inserted too deeply or an LMA is inserted forcefully in surrounding tissue, it may induce a hypopharyngeal injury, which can cause dysphagia and soft tissue emphysema [8]. It is important that an LMA should be inserted gently to avoid a possible injury to esophagus in pediatric patients. Professional person should be called if the insertion of LMA is failed after multiple trials and another methods which could keep the airway should be considered. As one of the causes of esophageal injury may be related to the suction of the respiratory tract, too high of a pressure should be avoided when an aspiration procedure is necessary, and it is mandatory to stop the procedure if bleeding occurs.

In conclusion, although an esophageal injury or perforation in pediatric patients is rare, when need an LMA insertion or a procedure such as aspiration or nasogastric tube insertion, it should be performed gently to avoid a possible injury to esophagus in pediatric patients.

\section{CONFLICT OF INTEREST}

No potential conflict of interest relevant to this article was reported.

\section{ACKNOWLEDGMENTS}

This work was supported by a 2-Year Research Grant of Pusan National University.

\section{ORCID}

Hee Young Kim https://orcid.org/0000-0001-7809-8739

Seung-Hoon Baek https://orcid.org/0000-0002-3533-7872

Yong Hoon Cho https://orcid.org/0000-0003-0170-9997

Joo-Yun Kim https://orcid.org/0000-0002-6525-6707

Yun Mi Choi https://orcid.org/0000-0002-8386-1265

Eun Ji Choi

Jung Pil Yoon

Jung Hyun Park

https://orcid.org/0000-0003-3731-0785

https://orcid.org/0000-0002-5928-8999

https://orcid.org/0000-0002-0519-4487

\section{REFERENCES}

1. Gander JW, Berdon WE, Cowles RA. Iatrogenic esophageal perforation in children. Pediatr Surg Int 2009;25:395-401.

2. Derbes VJ, Mitchell RE Jr. Hermann Boerhaaves' Atrocis, nec descripti prius, morbi historia, the first translation of the classic report of rupture of the esophagus, with annotations. Bull Med Libr Assoc 1955;43:217-40.

3. Panieri E, Millar AJ, Rode H, Brown RA, Cywes S. Iatrogenic esophageal perforation in children: patterns of injury, presentation, management, and outcome. J Pediatr Surg 1996;31: 890-5.

4. Burgard G, Möllhoff T, Prien T. The effect of laryngeal mask cuff pressure on postoperative sore throat incidence. J Clin Anesth 1996;8:198-201.

5. Dubost C, Kaswin D, Duranteau A, Jehanno C, Kaswin R. Esophageal perforation during attempted endotracheal intubation. J Thorac Cardiovasc Surg 1979;78:44-51.

6. Sticco A, Khettry A, Aldape C, Tortolani A, Velcek F. Iatrogenic esophageal perforation in a premature neonate: a current nonoperative approach to management. J Pediatr Surg Case Rep 2014;2:37-9.

7. van der Zee DC, Festen C, Severijnen RS, van der Staak FH. Management of pediatric esophageal perforation. J Thorac Cardiovasc Surg 1998;95:692-5.

8. Noma U, Ali R, Kane R, Donnelly M. Progressive dysphagia post laryngeal mask airway intubation. J Surg Tech Case Rep 2009;1:23-5. 